\title{
Production of Recombinant Replication-defective Lentiviruses Bearing the SARS-CoV or SARS-CoV-2 Attachment Spike Glycoprotein and Their Application in Receptor Tropism and Neutralisation Assays

\author{
Nazia Thakur ${ }^{1,2, *}$, Giulia Gallo ${ }^{1}$, Ahmed M. E. Elreafey ${ }^{1}$ and Dalan Bailey ${ }^{1, *}$
}

${ }^{1}$ Viral Glycoproteins Group, The Pirbright Institute, Pirbright, Woking, UK; ${ }^{2}$ The Jenner Institute, Nuffield Department of Medicine, University of Oxford, Oxford, UK

*For correspondence: Dalan.bailey@pirbright.ac.uk; nazia.thakur@pirbright.ac.uk

\begin{abstract}
[Abstract] For enveloped viruses, such as SARS-CoV-2, transmission relies on the binding of viral glycoproteins to cellular receptors. Conventionally, this process is recapitulated in the lab by infection of cells with isolated live virus. However, such studies can be restricted due to the availability of high quantities of replication-competent virus, biosafety precautions and associated trained staff. Here, we present a protocol based on pseudotyping to produce recombinant replication-defective lentiviruses bearing the SARS-CoV or SARS-CoV-2 attachment Spike glycoprotein, allowing the investigation of viral entry in a lower-containment facility. Pseudoparticles are produced by cells transiently transfected with plasmids encoding retroviral RNA packaging signals and Gag-Pol proteins, for the reconstitution of lentiviral particles, and a plasmid coding for the viral attachment protein of interest. This approach allows the investigation of different aspects of viral entry, such as the identification of receptor tropism, the prediction of virus host range, and zoonotic transmission potential, as well as the characterisation of antibodies (sera or monoclonal antibodies) and pharmacological inhibitors that can block entry.
\end{abstract}


Please cite this article as: Thakur, N. et al. (2021). Production of Recombinant Replication-defective Lentiviruses Bearing the SARS-CoV or SARS-CoV2 Attachment Spike Glycoprotein and Their Application in Receptor Tropism and Neutralisation Assays. Bio-protocol 11(21): e4249. DOI: 10.21769/BioProtoc.4249.

\section{Graphic abstract:}

\section{SARS-CoV and SARS-CoV-2 pseuodoparticle generation and applications}
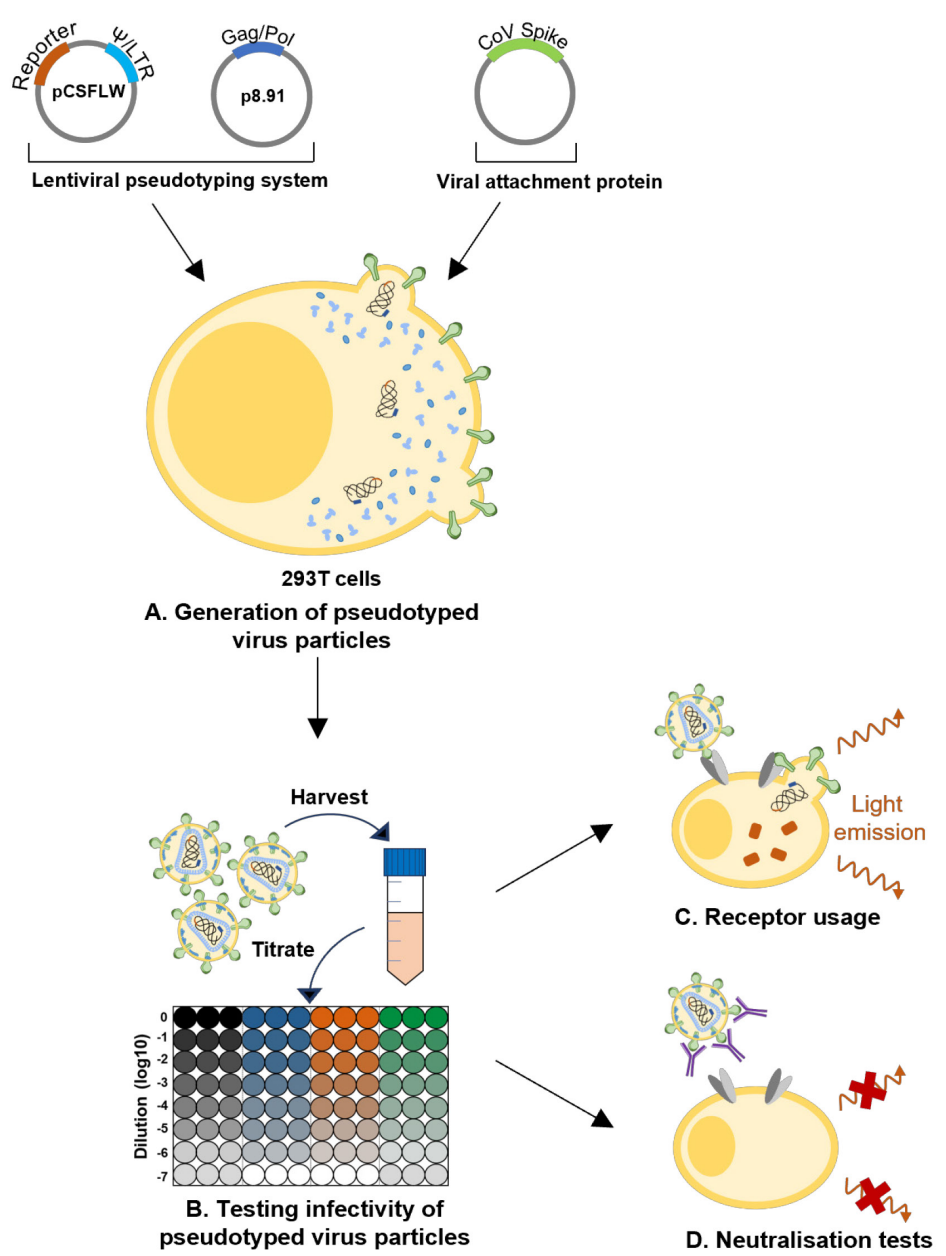

SARS-CoV and SARS-CoV-2 pseudoparticle generation and applications.

Keywords: SARS-CoV-2, SARS-CoV, Pseudotyped virus, Tropism, Neutralisation

[Background] Pseudoparticles are replication-defective viral particles obtained through expression of viral envelope glycoproteins on the surface of a recombinant virus, which provides the core components of the particle. Vesicular stomatitis virus (VSV), a rhabdovirus, and two lentiviruses - human immunodeficiency virus-1 (HIV-1) and murine leukaemia virus (MuLV) - are commonly used as viral vectors for pseudotyping (Takada et al., 1997; Wool-Lewis and Bates, 1998; Sharkey et al., 2001; Negrete et al., 2005; Grehan et al., 2015; Thakur et al., 2021). In our recent study, we successfully used a lentiviral-based system to study the interaction of severe acute respiratory syndrome coronavirus (SARS-CoV) and SARS-CoV-2 Spike (S) protein with its cellular receptor, angiotensin converting enzyme 2 (ACE2) (Conceicao et al., 2020). 
Please cite this article as: Thakur, N. et al. (2021). Production of Recombinant Replication-defective Lentiviruses Bearing the SARS-CoV or SARS-CoV2 Attachment Spike Glycoprotein and Their Application in Receptor Tropism and Neutralisation Assays. Bio-protocol 11(21): e4249. DOI: 10.21769/BioProtoc. 4249

SARS-CoV-2, the etiological agent of the ongoing COVID-19 pandemic, is a highly pathogenic betacoronavirus that requires handling at BSL-3 facilities, which are not always available in research laboratories. To allow work with SARS-CoV and SARS-CoV-2 at lower containment, the generation of viral particles pseudotyped with the Spike protein represents a safe and appealing surrogate. This technique allows (i) dissection of viral entry pathways, (ii) investigation of host cell susceptibility and tropism of the angiotensin converting enzyme 2 (ACE2) receptor, (iii) examination of inter-species transmission, (iv) assessment of the neutralising antibody responses in immunogenicity and seroepidemiological studies, and (v) efficacy assessment of small-molecule inhibitors that block viral entry. Notably, this technique has been applied to viral glycoproteins from a wide variety of viruses such as influenza hemagglutinin (Bertram et al., 2010), Nipah virus fusion and attachment proteins (Thakur et al., 2021), Ebola virus glycoprotein (Simmons et al., 2003), Chikungunya virus E1 (Salvador et al., 2009), hepatitis C virus E2 proteins (Hsu et al., 2003), and VSV glycoprotein (DePolo et al., 2000).

To generate lentiviral-based pseudoparticles of HIV-1, cells are co-transfected with the following plasmids: (i) HIV-1 packaging plasmid encoding for the core genes $\mathrm{Gag}$ and $\mathrm{PO}$, (ii) the transfer plasmid that encodes a firefly luciferase reporter gene flanked by HIV-1 regulatory LTR regions and the packaging signal, and (iii) a third plasmid encoding for the heterologous viral glycoprotein. Pseudoparticles possessing the viral glycoprotein of interest on their surface are assembled at the cellular membrane, from which they bud (Zufferey et al., 1997). Upon infection, the luciferase gene encoded by the lentivirus genome is expressed, allowing accurate quantification of viral entry.

\section{Materials and Reagents}

1. $50 \mathrm{ml}$ Falcon tubes (VWR International, catalog number: 734-0448)

2. Clear bottom 6-well tissue-culture treated plate (Scientific Laboratory Supplies, Falcon ${ }^{\mathrm{TM}}$, catalog number: 353046)

3. Pipette tips (STARLAB, catalog numbers: S1110-3700 [10/20 $\mu$ I XL Graduated TipOne $\left.{ }^{\circledR}\right]$; S11111206-C [200 $\mu$ l Yellow Bevelled TipOne ${ }^{\circledR}$ Tip]; S1112-17200 [1,250 $\left.\mu \mathrm{l} \mathrm{XL} \mathrm{Graduated} \mathrm{TipOne}{ }^{\circledR}\right]$ )

4. Serological pipettes (Corning, catalog numbers: 4101 [10 $\mathrm{ml}$ Stripette ${ }^{\mathrm{TM}}$ ]; 4051 [5 ml Stripette ${ }^{\mathrm{TM}}$ ]; 4251 [25 ml Stripette $\left.{ }^{\mathrm{TM}}\right]$ )

5. Opti-MEM ${ }^{\mathrm{TM}}$ (Thermo Scientific, Gibco ${ }^{\mathrm{TM}}$, catalog number: 11058021 , storage conditions: $4^{\circ} \mathrm{C}$, shelf life: 12 months)

6. Disposable weighing boats $85 \times 85 \times 24 \mathrm{~mm}$, PS, medium, white, anti-static (VWR, catalog number: $10770-448$, storage conditions: room temperature)

7. $7 \mathrm{ml}$ polycarbonate polypropylene screw cap bijous (container for storage of small-volume samples) (STARLAB, catalog number: E1412-0710)

8. 96-well Delta-treated (hydrophilic surface that promotes cell attachment and growth) White flatbottom plate (Fisher Scientific, Nunc, MicroWell, catalog number: 10182831)

9. Tissue culture flasks (Greiner Bio-One, catalog numbers: $660160\left[175 \mathrm{~cm}^{2}\right], 658170\left[75 \mathrm{~cm}^{2}\right]$ )

10. $1.5 \mathrm{ml}$ Microcentrifuge sterile Eppendorf tubes (STARLAB, TubeOne ${ }^{\circledR}$, catalog number: $\mathrm{S} 1615$ - 
5510)

11. Millex-GP syringe filter unit, $0.22 \mu \mathrm{m}$ filter, polythersulfone, $33 \mathrm{~mm}$, gamma sterilised (Merck, Millipore, catalog number: SLGP033RS, storage conditions: room temperature)

12. Human Embryonic Kidney 293T, HEK293T cells (ATCC ${ }^{\circledR}$, catalog number: CRL-3216 ${ }^{\mathrm{TM}}$, storage conditions: liquid nitrogen vapour phase)

13. Baby Hamster Kidney-21, BHK-21 cells $\left(\right.$ ATCC $^{\circledR}$, catalog number: CCL-10 ${ }^{\mathrm{TM}}$, storage conditions: liquid nitrogen vapour phase)

14. Plasmid DNA: ACE2 receptors (pDISPLAY expression vector, codon-optimised, N-terminal signal peptide [the murine Ig k-chain leader sequence], C-terminal HA-tag), SARS-CoV Spike, SARS-CoV-2 Spike (pcDNA3.1(+), codon-optimised, C-terminal FLAG-tag) (BioBasic, Canada [Conceicao et al., 2020]), p8.91, CSFLW, VSV-G (pcDNA3.1(+) expression vector) (available upon request), pcDNA3.1(+) (Thermo Scientific, Invitrogen, catalog number: V79020) and pDISPLAY ${ }^{\mathrm{TM}}$ (Thermo Scientifc, Invitrogen ${ }^{\mathrm{TM}}$, catalog number: V66020)

15. Sera or antibodies for neutralisation assays, with relevant biological risk assessment and ethical approvals in place

16. Dulbecco's modified Eagle's medium, DMEM (Merck, Sigma-Aldrich, catalog numbers: D5796 [with phenol red]; D1145 [phenol red free], storage conditions: $4^{\circ} \mathrm{C}, 12$ months)

17. Foetal bovine serum, FBS (Life Science Production, catalog number: S-001A-BR, $-20^{\circ} \mathrm{C}$ )

18. Penicilin-Streptomycin, $10,000 \mathrm{U} / \mathrm{ml}$ (Thermo Scientific, Gibco ${ }^{\mathrm{TM}}$, catalog number: 15240122 , storage conditions: $-20^{\circ} \mathrm{C}$, shelf life: 12 months)

19. Sodium pyruvate, $100 \mathrm{mM}$ (Thermo Scientific, Gibco ${ }^{\mathrm{TM}}$, catalog number: 11360070 , storage conditions: $4^{\circ} \mathrm{C}$, shelf life: 12 months)

20. EDTA (0.5 M), pH 8.0, RNase-free (Thermo Scientific, Ambion ${ }^{\circledR}$, catalog number: AM9269G)

21. $1 \times$ Trypsin-EDTA, $0.25 \%$, phenol red (Thermo Scientific, Gibco ${ }^{\mathrm{TM}}$, catalog number: 2520072 , storage conditions: $-20^{\circ} \mathrm{C}$ long-term, $4^{\circ} \mathrm{C}$ while in use, shelf life: 24 months)

22. TransIT-X2 ${ }^{\circledR}$ Dynamic Delivery System (Mirus, catalog number: MIR 6000, storage conditions: $20^{\circ} \mathrm{C}$, shelf life: 12 months)

23. Polyethyleneimine, PEI (Merck, Sigma-Aldrich, catalog number: 408727, storage conditions: $\left.4^{\circ} \mathrm{C}\right)$

24. Nuclease-free, autoclaved, $0.2 \mu \mathrm{m}$ filtered DEPC-treated water (Ambion, catalog number: AM9906, storage conditions: room temperature)

25. Hydrochloric acid 36.5-38.0\%, Bioreagent, for molecular biology (Sigma-Aldrich, catalog number: H1758-100 ml, storage conditions: room temperature)

26. Bright-Glo ${ }^{\mathrm{TM}}$ Luciferase Assay System (Promega, catalog number: E2650, storage conditions: $\left.-20^{\circ} \mathrm{C}\right)$

27. $55 \mathrm{ml}$ StarTub PVC reagent reservoirs (STARLAB, sterile individually wrapped, catalog number: E2310-1010)

28. DMEM-10\% (see Recipes)

29. Working solution of $1 \mathrm{mg} / \mathrm{ml} \mathrm{PEI}$ (see Recipes) 


\section{Equipment}

1. Microbiological safety cabinet, BSL-2 (CAS, Biomat 2 - class 2 complies with BS EN 12469:2000)

2. $\mathrm{CO}_{2}$ incubator (PHC Europe B.V., PHCbi, catalog number: MCO-170AICD-PE)

3. $-86^{\circ} \mathrm{C}$ ultra-low temperature freezer (PHCbi, Panasonic, vip plus, model: MDF-DU900V)

4. $-20^{\circ} \mathrm{C}$ Medical freezer with 14 storage drawers (Liebherr, Profiline, model: G5216)

5. $4^{\circ} \mathrm{C}$ refrigerator (VDW CoolSystems, Labcold, Sparkfree, model: RLV0217)

6. Sub aqua 5 plus water bath (Fisher Scientific, Grant, model: 13251183)

7. Automated pipettor for serological pipettes (Fisher Scientific, Thermo Scientific ${ }^{\top M}$, S1 Pipet Fillers, catalog number: 10072332)

8. Single-channel pipettes (Gilson, Pipetman L, catalog numbers: FA1001M [P2L 0.2-2 $\mu \mathrm{l}$ ],

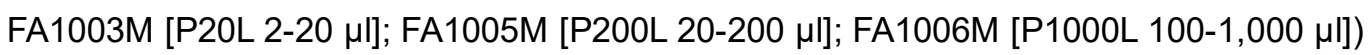

9. Multi-channel pipettes (Thermo Scientific ${ }^{\mathrm{TM}}$, Finnpipette ${ }^{\mathrm{TM}}$ F2 multichannel pipette, catalog numbers: 4662010 [8-well 5-50 $\mu$ l]; 4662070 [12-well 30-300 $\mu \mathrm{l}$ ])

10. Inverted microscope for cell culture (Leica microsystems, model: DMi1-S 40/0.45)

11. Haemocytometer (Fisher Scientific, Hirschmann ${ }^{T M}$ Bright Lined Counting Chambers, catalog number: 105289616)

12. Centrifuge machine (Kendo laboratory product, Sorvall Legend RT, EASYset, model: 75004373)

13. Benchtop autoclave (Fisher Scientific, Astell scientific, catalog number: 12755375)

14. GloMax ${ }^{\circledR}$ Discover Microplate Reader (Promega, catalog number: GM3000)

\section{Software}

1. Microsoft Excel (Microsoft 365 for Windows, www.microsoft.com)

2. GraphPad Prism (Version 8.4.2, GraphPad Software for Windows, San Diego, California USA, www.graphpad.com)

3. GloMax ${ }^{\circledast}$ Discover System Software (Version 3.2.3, Promega, Southampton, United Kingdom www.promega.co.uk)

\section{Procedure}

A. Generation of SARS-CoV-2 and SARS-CoV pseudotyped virus particles

1. Maintain HEK293T cells for pseudoparticle production in $25 \mathrm{ml}$ of DMEM-10\% (see Recipes) in a $75 \mathrm{~cm}^{2}$ tissue culture flask.

2. Seed HEK293T cells at a concentration of $7.5 \times 10^{5}$ cells per well in a 6-well plate in $3 \mathrm{ml}$ of DMEM-10\%, for the total number of wells required.

3. Agitate cells in the plate using a rapid up-down, left-right movement. This will ensure cells are evenly distributed and do not clump. Incubate at $37^{\circ} \mathrm{C}, 5 \% \mathrm{CO}_{2}$ overnight. 
Please cite this article as: Thakur, N. et al. (2021). Production of Recombinant Replication-defective Lentiviruses Bearing the SARS-CoV or SARS-CoV2 Attachment Spike Glycoprotein and Their Application in Receptor Tropism and Neutralisation Assays. Bio-protocol 11(21): e4249. DOI: 10.21769/BioProtoc.4249

4. The next day, set up transfection mixes in the afternoon. The seeded HEK293T cells should be between $60-80 \%$ confluent for optimal transfection efficiency. Set up transfections for the SARSCoV-2 S or SARS-CoV S plasmid, alongside an empty vector negative control (no glycoprotein, no GP) and a positive control. For instance, if the SARS-CoV-2 $S$ and SARS-CoV S plasmids are in a pcDNA3.1 backbone, use an empty pcDNA3.1 plasmid as your no GP control. Generally, a VSV-G plasmid is used as a positive control, as it is trans-encapsidated into the HIV-1 particle efficiently (i.e., it pseudotypes well).

5. In a sterile $1.5 \mathrm{ml}$ Eppendorf tube, add $100 \mu \mathrm{l}$ of Opti-MEM along with $0.6 \mu \mathrm{g}$ of p8.91 plasmid (encoding for HIV-1 gag-pol), $0.6 \mu \mathrm{g}$ of CSFLW plasmid (lentivirus backbone expressing Firefly luciferase), and $0.5 \mu \mathrm{g}$ of glycoprotein (SARS-CoV-2 S, SARS-CoV S or VSV-G) or empty vector (pcDNA3.1) per well. Incubate for $5 \mathrm{~min}$ at room temperature.

6. In a separate $1.5 \mathrm{ml}$ Eppendorf tube, add $100 \mu \mathrm{l}$ of Opti-MEM plus and $10 \mu \mathrm{l}$ of PEl $(1 \mu \mathrm{g} / \mathrm{ml})$ per transfection and incubate for $5 \mathrm{~min}$ at room temperature.

7. For each $100 \mu \mathrm{l}$ transfection mix of DNA in Opti-MEM, add $100 \mu \mathrm{l}$ of PEI in Opti-MEM and mix vigorously with a pipette ten times. Incubate at room temperature for $20 \mathrm{~min}$.

8. Add $200 \mu$ l of the volume of the transfection mix in a dropwise manner to each well of the 6 -well plate and incubate overnight at $37^{\circ} \mathrm{C}, 5 \% \mathrm{CO}_{2}$.

9. The next morning, use a serological pipette to gently remove the media from wells containing the transfection mix by tilting the dish towards you and aspirating from the edge of the well, being careful not to disturb the monolayer. Replace with $3 \mathrm{ml}$ of DMEM-10\%. Incubate overnight at $37^{\circ} \mathrm{C}, 5 \% \mathrm{CO}_{2}$ for $24 \mathrm{~h}$.

10. Harvest cell supernatants containing pseudotyped virus particles and transfer to a $50 \mathrm{ml}$ Falcon, pooling similarly transfected wells, and store at $4^{\circ} \mathrm{C}$. Replace the media with $3 \mathrm{ml}$ of DMEM-10\% per well, and incubate at $37^{\circ} \mathrm{C}, 5 \% \mathrm{CO}_{2}$ for $24 \mathrm{~h}$.

11. Harvest the cell supernatants containing pseudotyped virus particles and pool with pseudoparticles harvested the day before. Centrifuge at $2,500 \times \mathrm{g}$ for $10 \mathrm{~min}$ at $4^{\circ} \mathrm{C}$ to remove cellular debris.

12. Aliquot $4-5 \mathrm{ml}$ of pseudoparticles into bijous and freeze at $-80^{\circ} \mathrm{C}$ until further use.

NB: Larger volume of pseudoparticles can also be prepared in $10 \mathrm{~cm}^{2}$ culture dishes. The necessary cell seeding density, DNA concentrations and volumes required for this setup can be found in Table 1, with the corresponding values for the 6-well plate format noted alongside. Steps A9-A12 remain the same regardless of the dish size used, changing only the volume of media required. 
Please cite this article as: Thakur, N. et al. (2021). Production of Recombinant Replication-defective Lentiviruses Bearing the SARS-CoV or SARS-CoV2 Attachment Spike Glycoprotein and Their Application in Receptor Tropism and Neutralisation Assays. Bio-protocol 11(21): e4249. DOI: 10.21769/BioProtoc.4249.

Table 1. Quick-guide to generating lentiviral-based pseudotyped viruses

\begin{tabular}{|c|c|c|c|}
\hline & & 6-well plate format & $10 \mathrm{~cm}^{2}$ dish format \\
\hline $\begin{array}{l}\text { Cell seeding } \\
\text { density }\end{array}$ & HEK293T cells & $\begin{array}{l}7.5 \times 10^{5} \text { per well in } 3 \mathrm{ml} \\
\text { total volume DMEM- } 10 \%\end{array}$ & $\begin{array}{l}2 \times 10^{6} \text { per culture dish in } 10 \\
\mathrm{ml} \text { total volume DMEM-10\% }\end{array}$ \\
\hline \multirow{4}{*}{ DNA mix } & $\begin{array}{l}\text { Viral glycoprotein: } \\
\text { SARS-CoV-2/SARS-CoV Spike OR } \\
\text { pcDNA3.1 empty vector (NE, negative } \\
\text { control) OR } \\
\text { VSV-G (positive control) }\end{array}$ & $0.9 \mu \mathrm{g}$ & $1 \mu \mathrm{g}$ \\
\hline & p8.91 (HIV-1 gag/pol) & $0.6 \mu \mathrm{g}$ & $1 \mu \mathrm{g}$ \\
\hline & $\begin{array}{l}\text { pCSFLW (HIV-1 LTR, Firefly luciferase } \\
\text { gene) }\end{array}$ & $0.6 \mu \mathrm{g}$ & $1.5 \mu \mathrm{g}$ \\
\hline & Opti-MEM & $100 \mu \mathrm{l}$ & $200 \mu \mathrm{l}$ \\
\hline \multirow{2}{*}{$\begin{array}{l}\text { Transfection } \\
\text { reagent mix }\end{array}$} & PEI $(1 \mu \mathrm{g} / \mathrm{ml})$ & $10 \mu \mathrm{l}$ & $20 \mu \mathrm{l}$ \\
\hline & Opti-MEM & $100 \mu \mathrm{l}$ & $200 \mu \mathrm{l}$ \\
\hline $\begin{array}{c}\text { Total volume } \\
\text { per well }\end{array}$ & Opti-DNA + Opti-PEI mix & $200 \mu \mathrm{l}$ & $400 \mu \mathrm{l}$ \\
\hline Media & $\begin{array}{l}\text { Volume of DMEM-10\% to replace after } \\
\text { transfection or harvest }\end{array}$ & $3 \mathrm{ml}$ & $10 \mathrm{ml}$ \\
\hline
\end{tabular}

B. Testing SARS-CoV-2 and SARS-CoV pseudoparticle infectivity

1. Seed HEK293T cells at a density of $7.5 \times 10^{5}$ per well in a 6 -well plate in a total of $3 \mathrm{ml}$ of DMEM-10\%. Incubate overnight at $37^{\circ} \mathrm{C}, 5 \% \mathrm{CO}_{2}$.

2. Ensure plated cells are at $60-80 \%$ confluency to ensure optimal transfection efficiency. Set up transfection mixes to test pre-generated SARS-CoV-2 pseudoparticles. In a sterile $1.5 \mathrm{ml}$ Eppendorf tube, add $200 \mu \mathrm{l}$ of Opti-MEM along with $500 \mathrm{ng}$ of human ACE2 plasmid per well to be transfected. Bring the Tran/T-X2 transfection reagent to room temperature before use, add $2 \mu \mathrm{l}$ (for every $1 \mu \mathrm{g}$ of DNA) directly to the tube, and gently flick the tube to mix. Incubate at room temperature for $20 \mathrm{~min}$.

3. Add $200 \mu \mathrm{l}$ of the transfection mix dropwise to each well of the pre-plated cells and incubate overnight at $37^{\circ} \mathrm{C}, 5 \% \mathrm{CO}_{2}$.

4. Remove the media containing the transfection mix from the wells by tilting the dish towards you and aspirating from the edge of the well using a serological pipette, being careful not to disturb the monolayer. Add $1 \mathrm{ml}$ of DMEM-10\% per well and harvest the transfected cells. HEK293T cells have low adherence and come off the plate easily. As such, using the force of the pipetted liquid is sufficient to harvest cells, although care should be taken to ensure a single cell suspension is achieved without clumps. Trypsin should be avoided as this will unnecessarily cleave off the receptors, hampering future experimentation. Transfer to a $50 \mathrm{ml}$ Falcon and dilute cells to $2 \times 10^{5} / \mathrm{ml}$ with DMEM- $10 \%$.

5. Seed $100 \mu \mathrm{l}$ of diluted cells $\left(2 \times 10^{4}\right.$ per well $)$ into a flat, white-bottomed 96 -well plate and incubate overnight at $37^{\circ} \mathrm{C}, 5 \% \mathrm{CO}_{2}$. 
Please cite this article as: Thakur, N. et al. (2021). Production of Recombinant Replication-defective Lentiviruses Bearing the SARS-CoV or SARS-CoV2 Attachment Spike Glycoprotein and Their Application in Receptor Tropism and Neutralisation Assays. Bio-protocol 11(21): e4249. DOI: 10.21769/BioProtoc. 4249

6. The next day, thaw an aliquot of SARS-CoV-2 and/or SARS-CoV pseudoparticles, along with the negative (pcDNA3.1, no GP) and positive (VSV-G) controls. Titrate the pseudoparticles in a clear-bottomed 96 -well plate, starting with undiluted virus in the top row, and titrating 10-fold in DMEM-10\%, for a final volume of $100 \mu$.

7. Gently remove the media from the white-plate seeded with human ACE2-transfected cells and add $100 \mu \mathrm{l}$ titrated pseudoparticles. Incubate for $48 \mathrm{~h}$ at $37^{\circ} \mathrm{C}, 5 \% \mathrm{CO}_{2}$.

8. Remove the media from the wells by tilting the dish towards you and aspirating from the edge of the well using a multi-channel pipette and add $50 \mu \mathrm{l}$ Bright-Glo ${ }^{T M}$ diluted 1:1 with serum free, phenol red free DMEM. Incubate the plate in the dark for $5 \mathrm{~min}$ and then measure the luciferase signal on a GloMax Multi+ Detection System under the luminescence protocol with $0.5 \mathrm{~s}$ integration.

9. Export the CSV file generated on a USB flash drive for analysis using Microsoft Excel and plot data on GraphPad Prism.

C. ACE2 receptor usage screen using SARS-CoV-2 and SARS-CoV pseudotyped virus particles (Conceicao et al., 2020)

1. Maintain BHK-21 cells in $25 \mathrm{ml}$ DMEM-10\% in a $75 \mathrm{~cm}^{2}$ tissue culture flask. Seed BHK-21 cells in 24-well plates at $1 \times 10^{5} /$ well in DMEM-10\%. Incubate overnight at $37^{\circ} \mathrm{C}, 5 \% \mathrm{CO}_{2}$.

2. Ensure plated cells are at $60-80 \%$ confluency to ensure optimal transfection efficiency. Set up transfection mixes in $100 \mu \mathrm{l}$ of Opti-MEM along with 500ng of different species of ACE2expressing constructs or an empty vector control (e.g., pDISPLAY). Bring the Tran/T-X2 transfection reagent to room temperature before use and add $3 \mu \mathrm{l}$ for every $1 \mu \mathrm{g}$ of DNA directly to the tube and gently flick the tube to mix. Incubate at room temperature for $20 \mathrm{~min}$.

3. Add $100 \mu \mathrm{l}$ of the transfection mix dropwise to each well of the pre-plated BHK-21 cells and incubate overnight at $37^{\circ} \mathrm{C}, 5 \% \mathrm{CO}_{2}$.

4. Remove the media containing the transfection mix from the wells and add $0.5 \mathrm{ml}$ of $2 \mathrm{mM}$ EDTA in PBS per well to harvest the transfected cells. Transfer to a bijou and dilute cells to $2 \times 10^{5} / \mathrm{ml}$ with DMEM-10\%.

5. Seed $100 \mu \mathrm{l}$ of diluted cells $\left(2 \times 10^{4}\right.$ per well $)$ into a flat, white-bottomed 96-well plate and incubate overnight at $37^{\circ} \mathrm{C}, 5 \% \mathrm{CO}_{2}$.

6. Remove media from cells and infect with SARS-CoV-2 or SARS-CoV pseudoparticles equivalent to $10^{6}-10^{7}$ relative light units (RLU), or the no GP control at the same dilution and incubate for $48 \mathrm{~h}$ at $37^{\circ} \mathrm{C}, 5 \% \mathrm{CO}_{2}$.

7. Remove the media from the wells and add $50 \mu \mathrm{l}$ of Bright-Glo ${ }^{T M}$ diluted $1: 1$ with serum free, phenol red free DMEM. Incubate the plate in the dark for 5 min then read on a GloMax Multi+ Detection System under the luminescence protocol with $0.5 \mathrm{~s}$ integration.

8. Export the CSV file generated on a USB flash drive for analysis using Microsoft Excel and plot data on GraphPad Prism. 
Please cite this article as: Thakur, N. et al. (2021). Production of Recombinant Replication-defective Lentiviruses Bearing the SARS-CoV or SARS-CoV2 Attachment Spike Glycoprotein and Their Application in Receptor Tropism and Neutralisation Assays. Bio-protocol 11(21): e4249. DOI: 10.21769/BioProtoc. 4249

D. Neutralisation assay using SARS-CoV-2 and SARS-CoV pseudotyped virus particles

1. Prior to setting up neutralization assays, seed HEK293T cells at a density of $7.5 \times 10^{5}$ per well in a 6 -well plate in a total of $3 \mathrm{ml}$ of DMEM-10\%. Incubate overnight at $37^{\circ} \mathrm{C}, 5 \% \mathrm{CO}_{2}$.

2. Ensure plated cells are at $60-80 \%$ confluency to ensure optimal transfection efficiency. In a sterile $1.5 \mathrm{ml}$ Eppendorf tube, add $200 \mu \mathrm{l}$ of Opti-MEM along with $500 \mathrm{ng}$ of human ACE2 plasmid per well to be transfected. Bring the Tran $/ T$-X2 transfection reagent to room temperature before use and add $2 \mu \mathrm{l}$ for every $1 \mu \mathrm{g}$ of DNA directly to the tube and gently flick the tube to mix. Incubate at room temperature for $20 \mathrm{~min}$.

3. Add $200 \mu \mathrm{l}$ of the transfection mix dropwise per well of pre-plated cells and incubate overnight at $37^{\circ} \mathrm{C}, 5 \% \mathrm{CO}_{2}$.

4. Set up neutralisation assays by diluting sera/monoclonal antibodies (mAbs)/inhibitors considering the dilution series to be used and the final volume after addition of pseudoparticles. For example, sera to be titrated using a 2-fold dilution series starting at a 1:10 dilution would require $10 \mu \mathrm{l}$ sera per well in $100 \mu \mathrm{l}$ serum free DMEM. The same is applicable for mAbs or inhibitors with a known concentration.

5. Add $100 \mu$ l of diluted sera/mAbs/inhibitors in triplicate to the top row of a flat white-bottomed 96 well plate. Add $50 \mu \mathrm{l}$ of serum free media to all remaining wells. Remove $50 \mu \mathrm{l}$ from the top row and titrate 2-fold down the plate, mixing well before each titration. Do not titrate into the bottom row. This whole row will be used as the untreated control.

6. Thaw an aliquot of SARS-CoV or SARS-CoV-2 pseudoparticles and dilute in serum free DMEM, equivalent to $\sim 10^{6} \mathrm{RLU}$ and add $50 \mu \mathrm{l}$ per well, including the untreated controls. Incubate for 1 h at $37^{\circ} \mathrm{C}, 5 \% \mathrm{CO}_{2}$.

7. Remove the media from the 6-well plates transfected with human ACE2. Add $1 \mathrm{ml}$ of DMEM$10 \%$ per well and harvest the transfected cells. HEK293T cells have low adherence, so come off the plate easily; therefore, the force of the pipetted liquid should be sufficient to harvest cells (see B4 above). Transfer to a $50 \mathrm{ml}$ Falcon and dilute cells to $2 \times 10^{5} / \mathrm{ml}$ with DMEM-10\%.

8. Seed $100 \mu \mathrm{l}$ of diluted cells $\left(2 \times 10^{4}\right.$ per well) onto each well containing sera/mAb/inhibitor with pseudoparticles and the untreated controls. Incubate for $48 \mathrm{~h}$ at $37^{\circ} \mathrm{C}, 5 \% \mathrm{CO}_{2}$.

9. Remove the media from the wells and add $50 \mu \mathrm{l}$ of Bright-Glo ${ }^{\mathrm{TM}}$ diluted 1:1 with serum free, phenol red free DMEM. Incubate the plate in the dark for 5 min then read on a GloMax Multi+ Detection System under the luminescence protocol with $0.5 \mathrm{~s}$ integration.

10. Export the CSV file generated on a USB flash drive for analysis using Microsoft Excel and plot data on GraphPad Prism.

\section{Data analysis}

A. Testing SARS-CoV-2 and SARS-CoV pseudoparticle infectivity

1. After preparing a batch of pseudoparticles, their infectivity can be tested by titrating them on target cells that have been transfected to express the host receptor (ACE2) of the pseudotyped 
attachment protein (Spike) for SARS-CoV and SARS-CoV-2. Undiluted pseudotyped virus ("1") is titrated 10-fold with DMEM-10\% down a $96-$ well plate in triplicate ("10", "100", "1,000" etc.) (Figure 1A).

2. Measuring the luciferase signal of the pseudoparticles will generate a CSV file that can be exported onto a USB flash drive and analysed on Microsoft Excel. These results can then be plotted on GraphPad Prism to show the mean \pm SD for each pseudoparticle.

3. The no GP negative control serves as an indication of background luciferase signal, and only values above this at each corresponding dilution should be considered as a true luciferase signal for the pseudoparticles being tested (Figure 1B, black line). Generally, a minimum of $\sim 2$ log dynamic range between the no GP and the pseudotyped virus and a RLU signal between $10^{5.5}$ and $10^{7.5} \mathrm{RLU}$ (Figure 1B, shaded area) is sufficient for use in subsequent assays. The titration series will also help to determine the lowest usable dilution of the pseudoparticles to still obtain meaningful luciferase values above the background. Of note: the following data to be discussed was generated for illustrative purposes only.

4. For example, when considering the luciferase values obtained for SARS-CoV, although these are above the no GP control at the highest dilution, the difference between the two is only $\sim 1$ log, which falls outside our criteria for use (Figure 1B, blue line). When titrating the pseudoparticles, the luciferase values also fall quite quickly below the lower limit of the workable range at a 1:10 dilution and to the same values as the no GP control by the 1:1000 dilution, making the titre of this preparation of SARS-CoV pseudoparticles unsuitable for use in subsequent assays (Figure 1B).

5. In comparison, the luciferase signals obtained for SARS-CoV-2 are $\sim 2$ log above the background no GP control, and a dilution of 1:10 of the pseudoparticles would be within the workable range for use in subsequent assays, which is lost at a 1:100 dilution (Figure 1B, orange line).

6. The VSV-G pseudoparticles are a positive control within the assay, where the luciferase values observed should be above $10^{7} \mathrm{RLU}$ (Figure 1B, green line). 
A
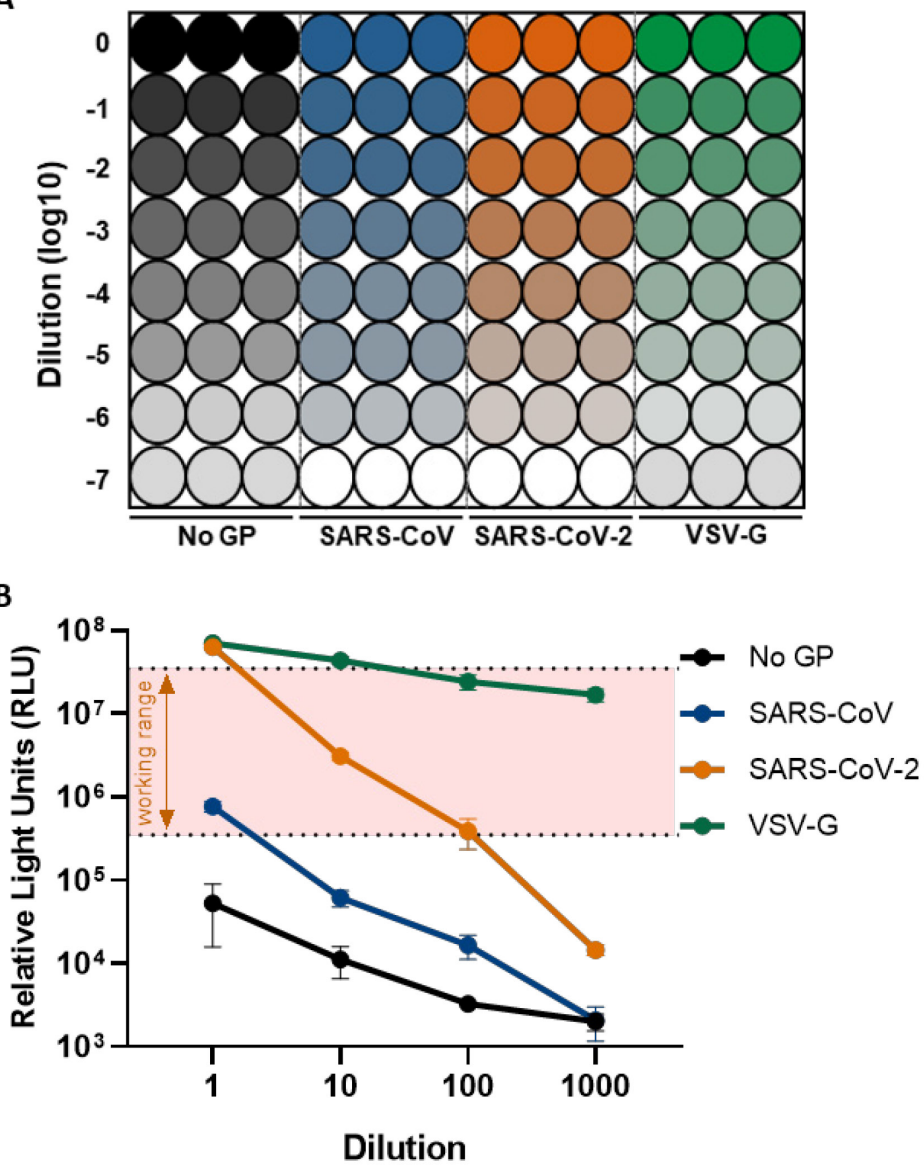

Figure 1. Testing the infectivity of SARS-CoV and SARS-CoV-2 pseudoparticles. (A) For SARS-CoV and SARS-CoV-2 pseudoparticle titrations, 10-fold serial dilutions of the supernatant are used to infect HEK293T cells transiently expressing the human ACE2 receptor in a white flat-bottomed 96 well-plate. Negative (no GP) and positive (VSV-G) controls are also included in the experiment. Each condition is tested in triplicate. (B) Two days after infection, signal luciferase values are measured and plotted as the mean \pm SD. The no GP control is indicative of the background, and only pseudoparticle values above this should be considered as true infectivity, matched at each dilution of the virus. The use of pseudoparticles for subsequent neutralisation assays and receptor usage screens should show 2 log dynamic range between the no GP and pseudotyped virus and fall between a working range of $10^{5.5}$ to $10^{7.5}$ (shaded area).

B. ACE2 receptor usage screen using SARS-CoV-2 and SARS-CoV pseudotyped virus particles

1. Infection of cells expressing various species ACE2 receptors with SARS-CoV or SARS-CoV-2 pseudoparticles set up in triplicate yields luciferase signals that can be plotted alongside each other (mean $\pm S D$ ) to depict raw values. These data also give an idea of the general trend of receptor tropism across different viruses (Figure 2A).

2. For example, water buffalo and goat ACE2 permit the entry of SARS-CoV and SARS-CoV-2 
Please cite this article as: Thakur, N. et al. (2021). Production of Recombinant Replication-defective Lentiviruses Bearing the SARS-CoV or SARS-CoV2 Attachment Spike Glycoprotein and Their Application in Receptor Tropism and Neutralisation Assays. Bio-protocol 11(21): e4249. DOI: 10.21769/BioProtoc.4249.

pseudoparticles well, which is less evident for little brown bat ACE2. Differences between viruses can be observed for civet ACE2, which permits the entry of SARS-CoV more efficiently than SARS-CoV-2 (Figure 2A). These experiments should be conducted at least three times on three separate occasions, with representative data shown. A subset of ACE2 receptors are shown in Figure 2A, but a more in-depth, wider analysis can be found in Supplementary Figure $3 A$ and $3 C$ in Conceicao et al. (2020).

3. Two negative controls are set up in this screen. The first is an empty vector control (pDISPLAY) to ensure any signal measured is solely from overexpression of the ACE2 receptor. The second is infection of cells with the no GP control pseudoparticle preparation to ensure luciferase signals can be attributed to the pseudotyped viruses and provides a baseline for the background (Figure 2A).

4. The raw luciferase signals can then be used to determine the relative usage of non-cognate host ACE2 receptors (water buffalo, civet, goat, little brown bat) to a known or cognate host receptor, in this case, human ACE2. The mean percentage from three separate experiments performed on different days are used to obtain these values. The luciferase value for human ACE2 is set to $100 \%$, and the luciferase values for unknown host receptors and the negative control are then expressed as a percentage relative to human ACE2.

5. These results can also be shown as a heatmap using a colour gradient to show different trends of receptor usage. For example, human ACE2 (100\%) is set as green. Expression lower than this is shaded from green to red, indicative of poorer ACE2 usage relative to human ACE2. Values above $100 \%$ are shown as a darker green, suggestive of ACE2 usage equivalent to or greater than human ACE2 (Figure 2B). A subset of ACE2 receptors are shown in Figure 2B, but a more in-depth, wider analysis can be found in Figure $2 \mathrm{~A}$ in Conceicao et al. (2020).

6. Further analysis can be carried out to compare the receptor tropism of different species ACE2 between SARS-CoV and SARS-CoV-2 by plotting the percentage values for each virus against each other on an $x y$ scatter graph, calculating the Pearson's correlation coefficient, and plotting a linear line of regression fitted with 95\% confidence intervals (data not shown). An example of such analysis can also be found in Supplementary Figure 5 in Conceicao et al. (2020). 
A
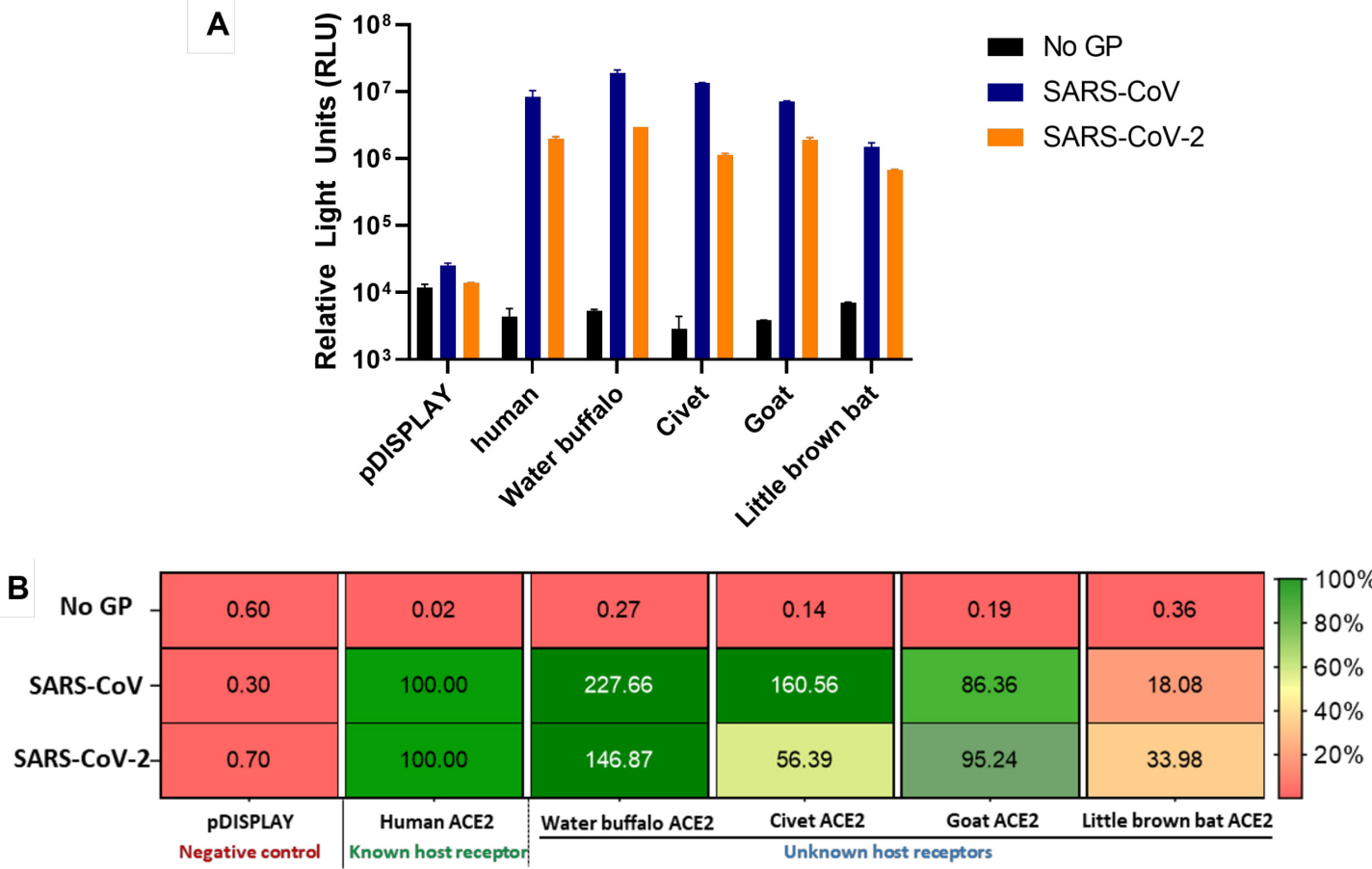

Figure 2. ACE2 receptor usage screen using SARS-CoV and SARS-CoV-2 pseudoparticles. In our study, pseudoparticles were used as a surrogate to live viruses to assess receptor tropism of SARS-CoV and SARS-CoV-2 with different species of ACE2 receptors. Pseudoparticles were employed to assess SARS-CoV and SARS-CoV-2 Spike glycoproteins' usage of ACE2 receptors from different species and presented as (A) raw luciferase signal values or (B) a percentage relative to human ACE2. Negative controls were included for pseudoparticles bearing an empty vector control (No GP) or mock-transfected with an empty vector in place of an ACE2 receptor (pDISPLAY). Data are presented as mean \pm SD of triplicate values, with each experiment performed three times on three separate occasions, and representative data shown.

C. Neutralisation assay using SARS-CoV-2 and SARS-CoV pseudotyped virus particles

1. Neutralisation assays using pseudotyped viruses are a low-biocontainment alternative to using live virus and can be performed in a relatively high-throughput manner. These neutralisation assays can be performed on mAbs, sera or any other drug or inhibitor that has the potential to inhibit viral entry. The data discussed herein have been generated for illustrative purposes only.

2. Inhibitors (mAbs/sera/drugs) of a known concentration can be titrated down a 96-well plate in triplicate to determine the extent of inhibition of SARS-CoV-2 entry. This is done by taking an average of the untreated controls and expressing the RLU values for each individual replicate of the mAb of interest relative to this. These can then be plotted as the mean $\pm S D$ and should be repeated a minimum of three times, with representative data shown:

(RLU individual replicate of $\mathrm{mAb} / \mathrm{RLU}$ average of untreated) $\times 100$ 
Please cite this article as: Thakur, N. et al. (2021). Production of Recombinant Replication-defective Lentiviruses Bearing the SARS-CoV or SARS-CoV2 Attachment Spike Glycoprotein and Their Application in Receptor Tropism and Neutralisation Assays. Bio-protocol 11(21): e4249. DOI: 10.21769/BioProtoc. 4249

3. The inhibitory concentration of $50 \%$ (IC50) should be indicated on a graph along with the untreated, no mAb control (100\%). Values below this IC50 line are indicative of S-mediated inhibition of entry, which can be calculated at each concentration. For example, mAb2 is able to inhibit SARS-CoV-2 S entry by $\sim 80 \%$ ( $20 \%$ of untreated) at $100 \mu \mathrm{g} / \mathrm{ml}$. The values obtained for $\mathrm{mAb} 2$ at all concentrations tested are below the IC50 value, so lower concentrations would need to be tested to determine the limit of inhibition. In contrast, mAb3 inhibits SARS-CoV-2 S entry by $\sim 90 \%$ at $100 \mu \mathrm{g} / \mathrm{ml}$, but at $12.5 \mu \mathrm{g} / \mathrm{ml}$, the inhibition is now above the IC50 threshold (Figure 3A).

4. There may also be examples of mAbs that do not inhibit SARS-CoV-2 S, as with mAb1. It may be possible that when inhibition of entry is not observed, a slight increase above the $100 \%$ threshold is seen. The mechanisms causing this increase are still unknown and under investigation, but for the purposes of this assay, the conclusion that the $\mathrm{mAb}$ does not neutralise SARS-CoV-2 $S$ is sufficient (Figure 3A). Examples of this sort of analysis can be found in Thakur et al. (2021).

5. When determining the inhibition of viral entry from individuals who have antibodies against SARS-CoV-2 $\mathrm{S}$, whether that be following natural infection or vaccination, a neutralising antibody titre is usually calculated to enumerate the level of SARS-CoV-2 S neutralisation. The simplest method of calculating this is by calculating the average RLU of the untreated controls and determining the IC50 value, i.e., $50 \%$ of the no sera control. The neutralisation titre is then calculated as the inverse of the dilution at which there is $50 \%$ inhibition of the no sera luciferase values in all triplicate wells. These titres can then be tabulated or plotted on a log scale.

6. For example, the titre of 256 for serum sample 1 and 512 for serum sample 3 indicates that IC50 was calculated at a dilution of 1:256 and 1:512, respectively. The conclusion that could be drawn from this is that serum sample 3 is able to neutralise SARS-CoV-2 S-mediated entry more efficiently than serum sample 1 and therefore has higher antibody titres (Figure 3B).

7. For serum sample 4 , this value has been plotted as 1,024 , which is the upper limit of detection (ULoD) for this assay. This means that this sample was able to inhibit $50 \%$ of the luciferase signal in all wells and at the lowest dilution that was tested. This serum would have to be retitrated with a broader dilution series to determine the neutralisation titre. For serum sample 2 , none of the wells in the dilution range yielded a recordable IC50. The neutralisation titre is therefore plotted as an arbitrary value below the lower limit of detection (LLOD), which in this case is 40 , but would be reported as $<40$ as the true titre is unknown (Figure 3B). Examples of IC50 neutralisation titres using this method can be found in Figure 4F in Thakur et al. (2021) and in Figure 2D and 2E in Graham et al. (2020). 
A

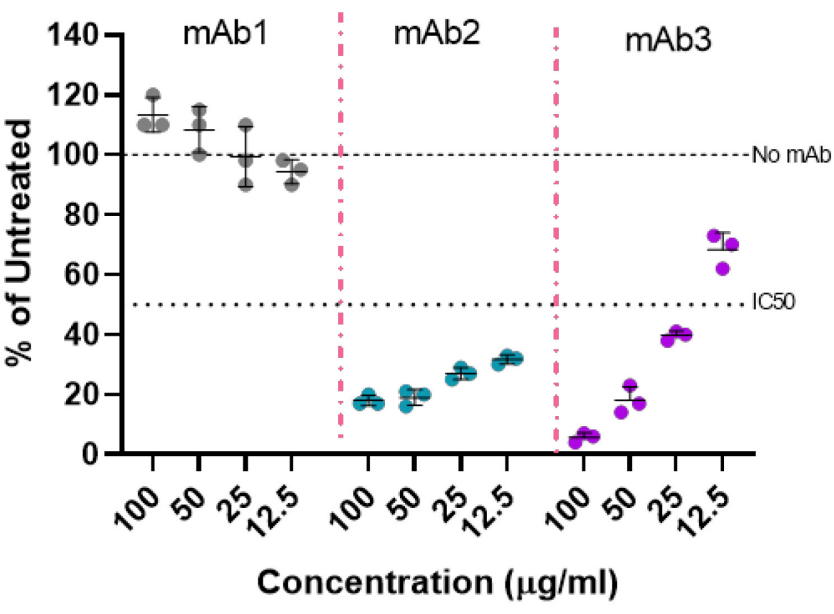

B

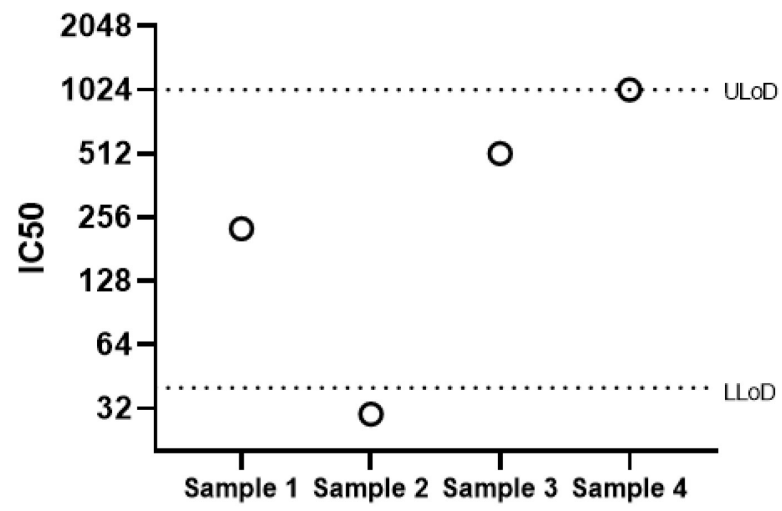

Figure 3. Neutralisation assays using SARS-CoV-2 pseudoparticles. SARS-CoV-2 Spike neutralisation assays were performed in the presence of (A) monoclonal antibodies (mAbs), presented as a percentage relative to untreated controls or (B) sera samples, with data expressed as neutralising titres. SARS-CoV-2 pseudoparticles were incubated with mAbs or sera for $1 \mathrm{~h}$ prior to addition of human ACE2-expressing HEK293T cells. Inhibition of SARS-CoV-2 Spike-mediated viral entry was determined by calculating the concentration (mAbs) or dilution (sera) at which there is a $50 \%$ reduction in luciferase signal (IC50). Data represent the mean \pm SD of triplicate values, with each experiment performed three times on three separate occasions, and representative data shown.

\section{Notes}

1. Procedure A, step 11 mentions centrifugation of pseudoparticle preparations prior to use in subsequent assays to remove cellular debris. Other protocols require further filtration of pseudoparticles using a $0.45 \mu \mathrm{m}$ filter before storage. This step is not carried out in our lab, as we have observed a reduction in infectivity following filtration.

2. Manufacturers usually recommend an optimal confluency of $60-80 \%$ for transfection. Therefore, it may be necessary to change the seeding density depending on the characteristics of the cells 
Please cite this article as: Thakur, N. et al. (2021). Production of Recombinant Replication-defective Lentiviruses Bearing the SARS-CoV or SARS-CoV2 Attachment Spike Glycoprotein and Their Application in Receptor Tropism and Neutralisation Assays. Bio-protocol 11(21): e4249. DOI: 10.21769/BioProtoc. 4249

used. For example, if the cell types used are larger (e.g., BHK-21 cells are larger than HEK293T cells) or have a high doubling rate, we recommend starting at a lower seeding density. On the other hand, if the cells are smaller, or have a slower growth rate, and are difficult to reach confluency (e.g., Calu3 cells) or indeed are suspension cells, you may want to start with a higher seeding density. In both instances, we recommend testing different seeding densities to find the optimal for any given experiment.

3. An example of optimal confluency of HEK293T cells prior to infection $(60-80 \%)$ is shown in Figure 4. Cells should be evenly distributed across the well (i.e., no clumping or aggregation in one area), with visible gaps in the monolayer (Figure 4A). The cell morphology of the HEK293T cells should appear flat and polygonal at confluence, which indicates adherence to the plastic (Figure 4B).
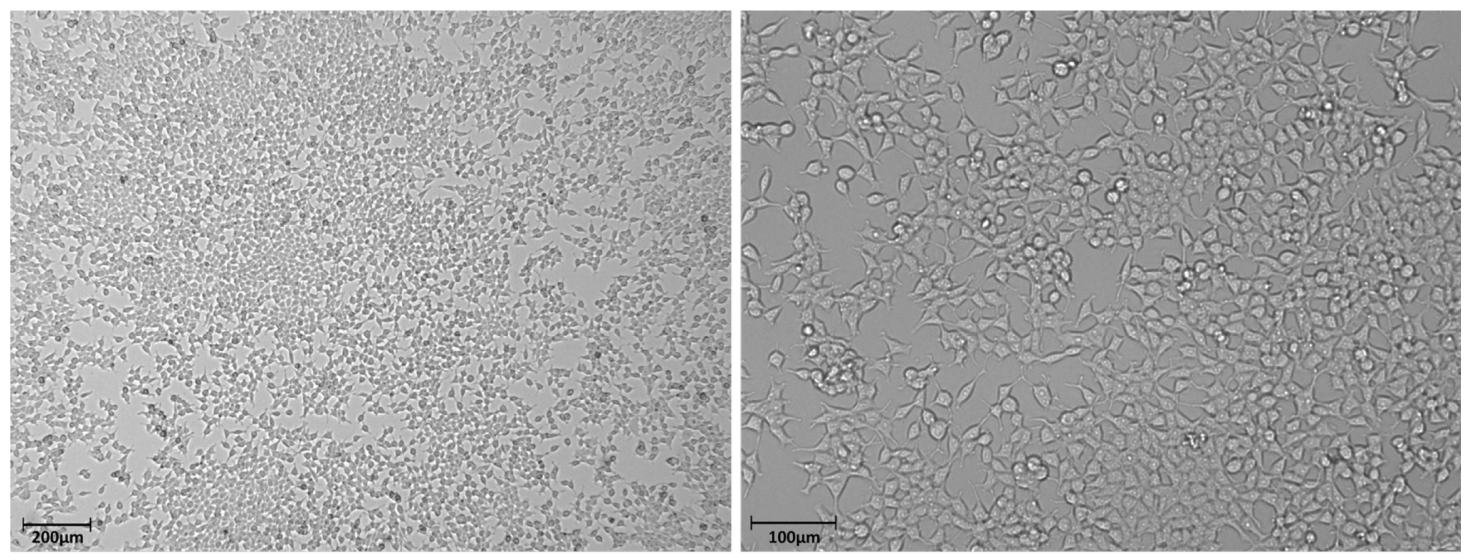

Figure 4. Brightfield image to illustrate $\mathbf{6 0 - 8 0 \%}$ optimal confluency of HEK293T cells. HEK293T cells were seeded at $7.5 \times 10^{5}$ in a 6 -well dish in $3 \mathrm{ml}$ of DMEM-10\%. On the following day, cells should be between $60-80 \%$ confluent for optimal transfection. (A) Example of $\sim 80 \%$ confluent HEK293T at 4× magnification, with cells appearing evenly distributed across the well and visible gaps. (B) Higher power magnification (10x) of HEK293T cells where cells should appear bright, flat and polygonal prior to transfection.

4. The concentrations of DNA used for transfection at various steps have been optimised for use in these assays. It is important that any plasmids used are optimised to account for variability in vector platform and codon-optimisation.

5. A higher signal (in the $10^{4}-10^{5} \mathrm{RLU}$ range) in the no GP control can sometimes be seen, likely the result of non-specific uptake of 'bald' pseudoparticles or debris from producer cells. To reduce this background signal, care should be taken to ensure producer cells are not transfected at low confluence as this can cause cytopathic effects (CPE) to develop.

6. All the experiments conducted here were performed with over-expressed ACE2 only. Coexpression of the serine protease TMPRSS2, which is required for S2 protein cleavage to S2', can facilitate the fusion of viral and cellular membranes and cleavage of the Spike protein (Hoffmann et al., 2020). TMPRSS2 was not included in our host range assays as we wanted to 
specifically examine the effects of different ACE2s - indeed, over-expression of TMPRSS2 led to ACE2 restrictions being masked (Conceicao et al., 2020).

7. Other formulae can be used to determine the IC50 value, yielding different titres. This is acceptable if the same method is used throughout analyses and the method used are described in full. Other formulae for calculating neutralisation titres include (1) using a non-linear regression analysis tool on GraphPad Prism after plotting data on an $X Y$ graph to interpolate neutralisation values (Ferrara and Temperton, 2018), (2) interpolating the point at which infectivity is reduced to $50 \%$ of the value of a no serum control sample using a fixed formula (Logan et al., 2016), and (3) determining the highest dilution at which complete neutralisation is seen in all replicate wells and considering other wells that also show neutralisation. Neutralisation is then calculated by inputting these values into a Spearman Karber formula (Lambe et al., 2021).

8. Neutralisation titres do not always need to be recorded as IC50 values. Other cut-off points can be chosen dependent on the level of neutralisation expected in a given assay, and to provide a more stringent measure of neutralisation (e.g., 80\% neutralisation, IC80).

9. The surface expression of different ACE2 receptors may differ, which may affect the level of Spike-ACE2 interaction leading to misinterpretation of results. Therefore, it is important to investigate and normalise the cell surface expression of the ACE2 receptors used. The mammalian ACE2 receptors described and used herein were HA-tagged at the C-terminus, which allowed detection of surface expression by flow cytometry. Additionally, protein expression was assessed by Western blotting (Conceicao et al., 2020).

\section{Recipes}

1. DMEM-10\%

DMEM supplemented with $10 \%$ FBS, $1 \%$ penicillin/streptomycin 10,000 U/ml, and 1\% $100 \mathrm{mM}$ sodium pyruvate, cultured at $37^{\circ} \mathrm{C}$ with $5 \% \mathrm{CO}_{2}$.

2. Working solution of $1 \mathrm{mg} / \mathrm{ml}$ PEI

a. Weigh the viscous liquid to get $50 \mathrm{mg} / \mathrm{ml}$ in water (e.g., $0.42 \mathrm{~g} \mathrm{PEI}+8.4 \mathrm{ml}$ water) and transfer to a sterile $50 \mathrm{ml}$ Falcon.

b. Place Falcon in a water bath set to $50^{\circ} \mathrm{C}$ and gently pipette up and down using a $1 \mathrm{ml}$ pipette until fully dissolved.

c. Dilute to $1 \mathrm{mg} / \mathrm{ml}$ with water (e.g., take $0.5 \mathrm{ml}$ of your $50 \mathrm{mg} / \mathrm{ml}$ stock and add $24.5 \mathrm{ml}$ water)

d. The solution in its current state will be very basic. Adjust $\mathrm{pH}$ to 7 using diluted hydrochloric acid.

e. Filter through a $0.22 \mu \mathrm{m}$ filter and aliquot into $1.5 \mathrm{ml}$ Eppendorf tubes.

f. Store at $-20^{\circ} \mathrm{C}$ long-term and at $4^{\circ} \mathrm{C}$ for up to one month while in use. 


\section{Acknowledgments}

This work was supported by the following grants to Dalan Bailey: a UK Research and Innovation (UKRI, https://www.ukri.org/) Medical Research Council (MRC) New Investigator Research Grant (MR/P021735/1), UKRI Biotechnology and Biological Sciences Research Council (UKRI - BBSRC, https://www.ukri.org/) project grants (BB/R019843/1 and BB/T008784/1, student funding), and Institute Strategic Programme Grant (ISPG) to The Pirbright Institute (BBS/E///00007034, $\mathrm{BBS} / \mathrm{E} / / / 00007030$ and BBS/E/I/00007039). The funders had no role in study design, data collection and analysis, decision to publish, or preparation of the manuscript.

We would like to acknowledge the research papers from which the protocols described herein have been derived from, which include: "The SARS-CoV-2 Spike protein has a broad tropism for mammalian ACE2 proteins" (Conceicao et al., 2020), "Micro-fusion inhibition tests: quantifying antibody neutralization of virus-mediated cell-cell fusion" (Thakur et al., 2021), and "Evaluation of the immunogenicity of prime-boost vaccination with the replication-deficient viral vectored COVID19 vaccine candidate ChAdOx1 nCoV-19" (Graham et al., 2020).

We would also like to thank the following for assistance in establishing the SARS-CoV and SARSCoV-2 pseudotype systems: Ed Wright (Viral Pseudotype Unit, University of Sussex), Nigel Temperton (Viral Pseudotype Unit, University of Kent), Brian Willett (University of Glasgow Centre for Virus Research), Emma Bentley and Giada Mattiuzzo (National Institute for Biological Standards and Control), and Michael Letko (National Institute of Allergy and Infectious Disease).

\section{Competing interests}

Authors declare no conflicts of interest.

\section{$\underline{\text { References }}$}

1. Bertram, S., Glowacka, I., Blazejewska, P., Soilleux, E., Allen, P., Danisch, S., Steffen, I., Choi, S. Y., Park, Y., Schneider, H., Schughart, K. and Pohlmann, S. (2010). TMPRSS2 and TMPRSS4 facilitate trypsin-independent spread of influenza virus in Caco-2 cells. J Virol 84(19): 10016-10025.

2. Conceicao, C., Thakur, N., Human, S., Kelly, J. T., Logan, L., Bialy, D., Bhat, S., StevensonLeggett, P., Zagrajek, A. K., Hollinghurst, P., et al. (2020). The SARS-CoV-2 Spike protein has a broad tropism for mammalian ACE2 proteins. PLoS Biol 18(12): e3001016.

3. DePolo, N. J., Reed, J. D., Sheridan, P. L., Townsend, K., Sauter, S. L., Jolly, D. J. and Dubensky, T. W., Jr. (2000). VSV-G pseudotyped lentiviral vector particles produced in human cells are inactivated by human serum. Mol Ther 2(3): 218-222.

4. Ferrara, F. and Temperton, N. (2018). Pseudotype Neutralization Assays: From Laboratory Bench to Data Analysis. Methods Protoc 1(1): 8. 
Please cite this article as: Thakur, N. et al. (2021). Production of Recombinant Replication-defective Lentiviruses Bearing the SARS-CoV or SARS-CoV2 Attachment Spike Glycoprotein and Their Application in Receptor Tropism and Neutralisation Assays. Bio-protocol 11(21): e4249. DOI: 10.21769/BioProtoc.4249.

5. Graham, S. P., McLean, R. K., Spencer, A. J., Belij-Rammerstorfer, S., Wright, D., Ulaszewska, M., Edwards, J. C., Hayes, J. W. P., Martini, V., Thakur, N., et al. (2020). Evaluation of the immunogenicity of prime-boost vaccination with the replication-deficient viral vectored COVID19 vaccine candidate ChAdOx1 nCoV-19. NPJ Vaccines 5(1): 69.

6. Grehan, K., Ferrara, F. and Temperton, N. (2015). An optimised method for the production of MERS-CoV spike expressing viral pseudotypes. MethodsX 2: 379-384.

7. Hoffmann, M., Kleine-Weber, H., Schroeder, S., Kruger, N., Herrler, T., Erichsen, S., Schiergens, T. S., Herrler, G., Wu, N. H., Nitsche, A., Muller, M. A., Drosten, C. and Pohlmann, S. (2020). SARS-CoV-2 Cell Entry Depends on ACE2 and TMPRSS2 and Is Blocked by a Clinically Proven Protease Inhibitor. Cell 181(2): 271-280 e278.

8. Hsu, M., Zhang, J., Flint, M., Logvinoff, C., Cheng-Mayer, C., Rice, C. M. and McKeating, J. A. (2003). Hepatitis C virus glycoproteins mediate $\mathrm{pH}$-dependent cell entry of pseudotyped retroviral particles. Proc Natl Acad Sci U S A 100(12): 7271-7276.

9. Lambe, T., Spencer, A. J., Thomas, K. M., Gooch, K. E., Thomas, S., White, A. D., Humphries, H. E., Wright, D., Belij-Rammerstorfer, S., Thakur, N., et al. (2021). ChAdOx1 nCoV-19 protection against SARS-CoV-2 in rhesus macaque and ferret challenge models. Commun Biol 4(1): 915.

10. Logan, N., McMonagle, E., Drew, A. A., Takahashi, E., McDonald, M., Baron, M. D., Gilbert, M., Cleaveland, S., Haydon, D. T., Hosie, M. J. and Willett, B. J. (2016). Efficient generation of vesicular stomatitis virus (VSV)-pseudotypes bearing morbilliviral glycoproteins and their use in quantifying virus neutralising antibodies. Vaccine 34(6): 814-822.

11. Negrete, O. A., Levroney, E. L., Aguilar, H. C., Bertolotti-Ciarlet, A., Nazarian, R., Tajyar, S. and Lee, B. (2005). EphrinB2 is the entry receptor for Nipah virus, an emergent deadly paramyxovirus. Nature 436(7049): 401-405.

12. Salvador, B., Zhou, Y., Michault, A., Muench, M. O. and Simmons, G. (2009). Characterization of Chikungunya pseudotyped viruses: Identification of refractory cell lines and demonstration of cellular tropism differences mediated by mutations in E1 glycoprotein. Virology 393(1): 33-41.

13. Sharkey, C. M., North, C. L., Kuhn, R. J. and Sanders, D. A. (2001). Ross River virus glycoprotein-pseudotyped retroviruses and stable cell lines for their production. $J$ Virol 75(6): 2653-2659.

14. Simmons, G., Reeves, J. D., Grogan, C. C., Vandenberghe, L. H., Baribaud, F., Whitbeck, J. C., Burke, E., Buchmeier, M. J., Soilleux, E. J., Riley, J. L., et al. (2003). DC-SIGN and DC-SIGNR bind ebola glycoproteins and enhance infection of macrophages and endothelial cells. Virology 305(1): 115-123.

15. Takada, A., Robison, C., Goto, H., Sanchez, A., Murti, K. G., Whitt, M. A. and Kawaoka, Y. (1997). A system for functional analysis of Ebola virus glycoprotein. Proc Natl Acad Sci U S A 94(26): 14764-14769.

16. Thakur, N., Conceicao, C., Isaacs, A., Human, S., Modhiran, N., McLean, R. K., Pedrera, M., Tan, T. K., Rijal, P., Townsend, A., Taylor, G., Young, P. R., Watterson, D., Chappell, K. J., 
Please cite this article as: Thakur, N. et al. (2021). Production of Recombinant Replication-defective Lentiviruses Bearing the SARS-CoV or SARS-CoV2 Attachment Spike Glycoprotein and Their Application in Receptor Tropism and Neutralisation Assays. Bio-protocol 11(21): e4249. DOI: 10.21769/BioProtoc.4249.

Graham, S. P. and Bailey, D. (2021). Micro-fusion inhibition tests: quantifying antibody neutralization of virus-mediated cell-cell fusion. J Gen Virol 102(1).

17. Wool-Lewis, R. J. and Bates, P. (1998). Characterization of Ebola virus entry by using pseudotyped viruses: identification of receptor-deficient cell lines. J Virol 72(4): 3155-3160.

18. Zufferey, R., Nagy, D., Mandel, R. J., Naldini, L. and Trono, D. (1997). Multiply attenuated lentiviral vector achieves efficient gene delivery in vivo. Nat Biotechnol 15(9): 871-875. 